\title{
Preface: The Presumption of Innocence
}

\author{
Liz Campbell $\cdot$ James Chalmers $\cdot$ Antony Duff
}

Published online: 25 February 2014

(C) Springer Science+Business Media Dordrecht 2014

Common lawyers are accustomed to the presumption of innocence being described as a "golden thread" running "[t]hroughout the web" of the criminal law: "that it is the duty of the prosecution to prove the prisoner's guilt" (Woolmington v DPP [1935] AC 462 per Viscount Sankey LC at 481). But although the language of "golden thread" is memorable and oft-quoted, the presumption of innocence must mean more than this: it is not simply a restatement of the burden of proof in a criminal trial.

Once this simple point is recognised, a whole host of more complex questions arise. For example: what, precisely, is the scope of the principle? Is this a matter on which consensus is possible or desirable? What role does the presumption have to play in pre-trial proceedings, in decisions by prosecutors? Does the presumption have consequences for the substantive criminal law, or can legislators blunt its impact by defining criminal offences so as to deprive the presumption of its bite? Can legislators troubled by the practical constraint the presumption might place on their choices avoid it by resort to mechanisms beyond the criminal process?

The contributions to this symposium, based on workshops held at the University of Aberdeen in February 2012 and the University of Minnesota in May 2012, seek to engage with a range of these questions. The contributions of Weigend, Stuckenberg and Roberts discuss the central meaning, and components of the presumption. Lippke considers the implications of the presumption for the work of prosecutors, while Husak explores a more specific aspect of the prosecutor's role in the form of deferred prosecution agreements, and Murray examines the application of the presumption in a specific prosecution, that of Dominique Strauss-Kahn in New York in 2011. Baradaran explores the connections between due process and the presumption, while Stewart argues that the right which the presumption embodies conditions the entire pre-trial process. Clark discusses its connection with the work of jurors and their responsibility for verdicts of conviction. Tomlin discusses its possible implications for the process of determining sentences.

L. Campbell · J. Chalmers · A. Duff $(\bowtie)$

Stirling, UK

e-mail: r.a.duff@stir.ac.uk 
On the question of whether the presumption has consequences for the substantive content of the criminal law-a claim which receives a sceptical response in the contributions of Roberts and Stewart-Tadros clarifies earlier work on the subject, arguing that a "purely procedural" conception of the presumption "has absurd implications". Ulväng considers how certain aspects of the criminal law may threaten the presumption, while Shiner explores its application in the case of corporate defendants. Ferzan's essay concludes the symposium by examining how the presumption might have consequences outside of the criminal justice system, by constraining the scope of civil preventive regimes.

The Aberdeen workshop was made possible by a grant from the Modern Law Review; the Minneapolis workshop was funded by the Robina Institute of Criminal Law and Criminal Justice; grateful thanks are due to these sponsors. Thanks are also due to the commentators on the draft papers discussed at the workshops, and to all the participants in the workshops. 